\title{
Analysis on the Electronic Business Enterprise Supply Chain Management Optimization
}

\author{
Ningning Pan \\ Hebei College of Science and Technology, Baoding, 071000, China
}

Keywords: Supply chain management, Electronic commerce, Management mode

\begin{abstract}
With the development of society, the Internet and information technology have developed dramatically. The development of electronic information technology promotes e-commerce to become a new mode of commercial activity. And this new business model has brought a great change in the control of business activities, consumption patterns and business idea. At the same time, as a new management and operation pattern the supply chain is also under the influence of electronic commerce.
\end{abstract}

\section{Introduction}

In recent years, with the emergence of global manufacturing, supply chain has been widely applied in manufacturing management, and has become a popular emerging management mode. The development of information technology promotes the change in enterprise organization structure and the transformation of the enterprise management system. Nowadays, many enterprises adopt the management pattern of "vertical integration", and this kind of management mode can exert its effect in relatively stable environment, and cannot play its proper role in today's complicated market environment. At this point, "horizontal integration" is born at the right moment, and supply chain management is the typical representative of "horizontal integration" management thought. In traditional supply chain relationships, it is difficult to match supply and demand. But with the electronic commerce, the transparency of enterprise supply chain has been increased, which makes the enterprises break through the limitations and make better use of all kinds of marketing channels to find partners. It also makes the most difficult link of matching supply and demand in the supply chain easier. At the same time it also broadens the product market. Therefore, how to use electronic commerce to strengthen the enterprise supply chain management has important practical significance for the construction of e-commerce supply chain.

\section{An overview of the relevant theories}

\section{An overview of electronic commerce}

The concept of electronic commerce

Along with the continuous development and popularization of computer technology, the Internet and information technology, from the 1990s to now, enterprises gradually began to use the Internet and electronic technology to engage in business activities. People call this emerging business activity which uses computer information network as platform electronic commerce. In particular, the electronic commerce refers to the sum of computer information networks for business activities including electronic method, and e-commerce has narrow and broad senses. Narrow sense of electronic commerce means to carry out a variety of business activities on the computer network. And the enterprise interconnects internal network, external network, the Internet as well as employees, customers, and suppliers. Such activities are e-commerce. Generalized e-commerce not only includes creating profitable business activities, but also includes other activities with the help of network and information technology to make profit. 


\section{The basic theory of supply chain management}

\section{The concept of supply chain}

The concept of supply chain is the product of social production, and the concept is in developmental change. Its early theory believes that supply chain is a process in which purchasing raw materials and components are passed to the customers through the production convert and sales process. The concept is limited within the enterprise, but with the development of market economy and enterprise business, the concept of the supply chain is expanded, and its scope is extended to the relationship among enterprises and it pays more attention to the relationship among enterprises.

The concept of supply chain management

The so-called supply chain management refers to use the systematical point of view to plan and control logistics, information flow and capital flow, and integrate each link of the supply chain to reduce consumption and waste and achieve to meet customer's needs and ensure the efficiency optimization of the entire supply chain and the maximization of interests, making each link of the supply chain as a whole. On the premise of guarantee the customer's satisfaction and reduce cost and waste to prompt enterprises to enhance the efficiency of management and competitiveness.

The basic thought of supply chain management

Guided by market and customer demand is the basic thought of supply chain management. It requires increase the competition rate and market share rate with the lead of core enterprise. At the same time ensure the maximum satisfaction of customers as the goal to achieve the win-win purpose. And achieve the effective planning and control for the whole supply chain link to unify customers, distributors, suppliers and service providers and into an organic whole and constitute a complete network chain structure to form a competitive strategic alliance.

\section{The structure analysis on traditional supply chain management}

\section{The traditional supply chain management}

Traditional supply chain management is to connect specified suppliers, distributors, retailers and customers through the communication. Because it focuses on the internal contact and lack of flexibility, the management cost is high, while the efficiency is low. At the same time, problem of one link can lead to paralysis of the entire supply chain.

The problems existing in the traditional supply chain management

1). Emphasizing competition rather than cooperation is one of common problems in the traditional supply chain management. The relationship between the various supply nodes is treated as trading partners rather than cooperative partners. Thus there is more competition than cooperation, which leads to loss at both sides between each node of the supply chain.

2). Lack of service platform and electronic trading means, lack of the corresponding market mechanism, lack of standard information service platform and electronic trading platform and cannot communicate with customers timely, which leads to customer dissatisfaction, and damages enterprise image.

3). The supply and demand information is inaccurate, which leads to the lagging information. Because customer information is not accurate, one-side contract breach increases and the supply chain information is not fluent, which causes unnecessary loss.

\section{Supply chain management under the electronic commerce}

\section{Electronic commerce and supply chain management}

As a new management mode, supply chain management is the result that the enterprise adapted to global competition after the 21 st century. it makes coordination and management for the whole supply chain, emphasis on cooperation and information resource integration, makes rapid response to market to create value for users. But because of relative lag of the application of information technology and network development, the advantage of the supply chain management can't be fully expressed. Now although there are some enterprises that have adopted some advanced information 
technology systems, it is limited to the internal. The connection between the partners and customers is still the weak link of supply chain management.

The development of electronic information technology and computer information technology promotes e-commerce to become the effective way to enhance the efficiency of the enterprise competitiveness for now and even for the future. The emergence of e-commerce has changed the form of commodities trading, and provides a higher quality service for consumers.

The combination of supply chain management and electronic commerce makes a new research hotspot, namely the e-commerce supply chain management (e- SCM).The core of electronic commerce is the efficient management of enterprise information and establish unobstructed information flow between enterprises and customers.

\section{The characteristics of e-commerce supply chain management}

\section{Personalized service}

Under the electronic commerce mode, enterprise breaks the boundaries of time and space. The whole process of production and consumption achieves a high degree of unity. This makes each link of the supply chain more efficient and flexible, and creates a good condition to provide high quality personalized services to customers.

\section{Information sharing and integration}

The supply chain management under the e-commerce environment makes the entire transaction process become more convenient, and also improves the quality and efficiency of the information flow, capital flow and logistics, and provides a better contact among them. It greatly improves the accuracy and the efficiency of information transfer.

The uniqueness of the management

Compared with the traditional supply chain management, e-commerce supply chain management has its own unique management style, because the changeful environment requires employees to improvise and work voluntarily. It will arouse the enthusiasm and initiative of the employees.

Efficient marketing channel

Establish cooperation with distributors and retailers through the electronic commerce, and get commodity sales messages through the information system. Making sales and inventory deployment on the basis of these messages can greatly improve the efficiency of marketing and customer satisfaction.

\section{The application of electronic commerce in supply chain}

1). The company's daily activities and communication between staff. Through the internal network, different divisions of the company and employees can communicate and exchange information in time. This realizes the "paperless office", saves the time and expenses.

2 ). The business coordination between inventory and transportation. Through the internal network, inventory planning personnel can easily see the warehouse situation in time and arrange the material delivery in a timely manner.

3 ). The coordination between the supply and purchase. Other stuff that can be viewed via an external network, and view the supplier's product information. Make order according to the request, exchange the information and negotiate between suppliers.

4). The coordination among sales organization and wholesaler and retailer. Sales organization can broadcast the goods through the Internet propaganda, and keep in touch with customers, get information feedback from the production planning department, make reasonable plan to help the production department.

5). Provide high-quality customer service. Through Internet electronic commerce system of the, enterprise can better communicate with the customer, at the same time can carry on the feedback in time. This makes the enterprise provide more high-quality services, and set up a better reputation for the enterprise. 


\section{Problems existing in supply chain management in the electronic commerce environment}

\section{Low degree of information technology application level}

The development of information technology accelerates the enterprise informatization process. Applying the information technology to supply chain management can improve the efficiency of the operation of supply chain management and strengthen the power of enterprise management decision. Therefore, information technology often determines the quality and efficiency of the whole supply chain. But in China, in the process of implementing supply chain management, the use of information technology is not sufficient. Enterprise electronic commerce development is slow. This is due to the immature market economy and the undeveloped IT industry in our country. Enterprise infrastructure is weak and the information technology application's enthusiasm is not high. Thus the technology application level of supply chain management in China was lagged behind.

\section{The inefficiency of supply chain management}

Due to restriction of the economic system and the imperfection of market economy, supply chain appears "ox tail effect", which makes the supply chain management inefficient. And the root cause of this phenomenon is due to the lack of communication between enterprises and it leads to long-term information block.

\section{The low degree of integration within the supply chain}

In recent years, with the development of supply chain management in China, the benefit it brings to the enterprise has become the focus of attention. Supply chain management mainly includes two aspects, one is the enterprise internal integration, and the second is the integration between enterprises. And there are many problems at the time of execution, which makes the integration degree within the whole supply chain is very low.

\section{The enterprise did not establish good cooperative relations}

External integration between enterprises is the key part of the whole supply chain integration. It can connect the suppliers and customers effectively, realize efficient supply chain management through the coordination management. However, cooperative partnership between enterprises is the key to successful integration.

\section{The optimization measures of e-commerce supply chain management in Chinese enterprise}

\section{Give full play to the role of e-commerce in enterprise supply chain}

Today, electronic commerce is occupying more and more important status in the supply chain management. On the supply chain, business subject and business activities are varied. Therefore supply chain must be collaborative. And the implementation of collaborative must rely on modern tools. This requires the electronic commerce to play a bigger role in enterprise supply chain management. Enterprises issue orders at random according to the demand through the extranet to browse supplier catalogue. After supplier receives orders, audit personnel can check the inventory through the internal network, and consider whether to accept the order according to the seller's credibility and various aspects of factors, and communicate with suppliers through the network.

\section{To strengthen the bonding effect of the supply chain in the process of financing}

The integration of electronic commerce on supply chain can complete the integration of goods flow, information flow and capital flow. In the past, enterprises often tend to ignore the integration of capital flows. In the condition of European and American economic crisis, the supply chain financing became the new focus. And at present, the supply chain financing is also very important for the integration of supply chain management. 


\section{Promote the agility of supply chain in electronic commerce environment}

Due to the increasing global market competition, many enterprises have chosen to rely on its own resources to adjust. And the emergence of electronic commerce provides the realization of agile manufacturing. Through e-commerce, consumers have more choices in a wide variety of goods, and because of consumers' new aesthetic criterion, commodity flow shows characteristics of small amount and variety. The demand also causes the agility of supply chain. However, this requires a lot of technical support.

\section{Establish a good cooperative partnership}

The external integration of enterprise supply chain is the most important part in the entire integration process. Therefore, to establish a good partnership is the key to the success of supply chain management integration. Cooperation between the enterprises can obtain more useful information, for example, the suppliers could sign contracts through Internet negotiation, exchange information, make up for the lack of their own, avoid risk to prompt the continuous optimization of supply chain management.

\section{Conclusion}

The development of e-commerce is the inevitable result of economic globalization and information technology development. it plays a unique role to change the original mode and structure of supply chain management. With the full optimization of the utilization of resources, it reduces the cost and improves the quality of services. For consumers, the application of electronic commerce makes consumers have the right to shop around, so as to meet the personalized needs of consumers. In e-commerce era, the traditional supply chain management has been unable to meet the personalized needs and business requirements of more customers. Therefore we must combine e-commerce and supply chain management. Under the background of the new era, requires the supply chain has to break the boundaries of geography and technology, which requires enterprises to use the new theory of new methods and techniques to solve the problem of supply chain management. The emergence of e-commerce solved this problem, and makes the optimization of supply chain management become simpler.

\section{References}

[1] Yang Kai. is Analysis on the application of E-commerce in mass customization oriented supply chain management. Market Weekly (Theory Study). 2007 (01)

[2] Zhang Qinghuan. Analysis on logistics management and logistics distribution under the electronic commerce, Era of Economic and Trade, 2008 (S4)

[3] Meng Xiaoming, Zhang Jianhua. Research on problems and countermeasures of supply chain management in the electronic commerce environment, Journal of District Economy, 2006 (8)

[4] Wu XianGang. On the reconstruction and improvement of enterprise supply chain management in the electronic commerce environment, Tribune, 2007 (03)

[5] He Zhenqi, Chen Hongzhi. Study on global enterprises supply chain management mode in E-commerce era. Logistics Technology, 2007 (08) 